Vol 12, Issue 6, 2019

\title{
TERMINALIA ARJUNA TRANSDERMAL MATRIX FORMULATION CONTAINING DIFFERENT POLYMER COMPONENTS
}

\author{
DINANATH GAIKWAD*, NAMDEO JADHAV
}

Department of Pharmaceutics, Bharati Vidyapeeth College of Pharmacy, Kolhapur, Maharashtra, India. Email: gdinanath@gmail.com Received: 16 February 2019, Revised and Accepted: 06 May 2019

\begin{abstract}
Objective: The objective of this research work was to prepare a transdermal matrix formulation containing different polymer components for topical delivery.

Methods: Terminalia arjuna bark extract loaded transdermal patches were prepared using solvent casting technique with different amount of chitosan and Eudragit RL 100 batches were prepared according to $3^{2}$ factorial designs.

Results: The transdermal patches prepared were evaluated for different physicochemical properties, determination of drug content, in vitro diffusion study, ex vivo study, skin irritation study, and stability study. Infrared studies indicate the absence of chemical interaction or any changes in the chemical composition of extract during the preparation of transdermal patch. In vitro diffusion study and ex vivo diffusion study of optimized batch S3 showed drug releases to 74.56-69.12\%, respectively, up to $12 \mathrm{~h}$. Skin irritation study indicates that the extract and excipients used in the patch do not show any irritating effect on the skin. All the prepared transdermal matrix formulations were found to be stable on storage.
\end{abstract}

Conclusion: It can be concluded that prepared matrix formulation containing different polymer components can be used for transdermal delivery for the treatment of chronic ailments such as cardiovascular disorder.

Keywords: Chitosan, Eudragit RL 100, Terminalia arjuna, Transdermal.

(C) 2019 The Authors. Published by Innovare Academic Sciences Pvt Ltd. This is an open access article under the CC BY license (http://creativecommons. org/licenses/by/4. 0/) DOI: http://dx.doi.org/10.22159/ajpcr.2019.v12i6.32643

\section{INTRODUCTION}

Transdermal matrix system (TMS) encompasses the uniform dispersion of drug in the polymeric matrix that has a hydrophilic or hydrophobic identity. TMS has been showing an increased interest than other delivery methods, one of which is to avoid the metabolism of the first pass effect on the liver and able to deliver the drug in a controlled manner directly to the blood vessels. Transdermal administration can give local therapeutic effect as well as a systemic effect [1-3]. TMS imparts a leading advantage beyond injectables and oral routes by elevating patient compliance, minimize dosing frequency, painless, and cost effective. TMS can deliver medicines through the skin portal to systemic circulation at a predetermined rate over a prolonged period [4].

Terminalia arjuna is a deciduous and evergreen tree, which has been used in heart failure, ischemia, cardiomyopathy, atherosclerosis, myocardium necrosis, blood diseases, anemia, venereal, and viral disease. It is used in the treatment of several ailments and showed hypocholesterolemic, antibacterial, antimicrobial, antitumoral, antiallergic, antifeedant, antifertility, and anti-HIV activities. T. arjuna stem bark contains glycosides, ample quantities of flavonoids, tannins, and minerals [5-8]. Phytoconstituents of T. arjuna have been well reported to exert antioxidant, anti-inflammatory, lipid-lowering effect, and cardiotonic effect [9].

Over the past few decades, polymers such as guar gum, chitosan, carrageenans, sodium alginate, pectin, xanthan gum, gellan gum, and agar have been widely used which can be used in various ways in the formulation of targeted and controlled drug delivery systems as they have different derivatizable groups, a wide range of molecular weight, and varying chemical composition. Chitosan is a linear polysaccharide composed of randomly distributed $\beta-(1-4)$ linked D-glucosamine (deacetylated unit) and N-acetyl-D-glucosamine (acetylated unit) produced by the deacetylation of chitin [10]. The amino group in chitosan has a pKa value of around 6.5, which leads to a protonation in acidic to a neutral solution with a charge density dependent on $\mathrm{pH}$ and the degree of acetylation value which makes chitosan water soluble and bioadhesive that readily binds to negatively charged surfaces such as mucosal membranes. The properties of chitosan allow it to be used in transdermal drug delivery effectively. Eudragit RL 100 (ERL 100) is a copolymer of acrylic acid and methacrylic acid esters with a low content in quaternary ammonium groups. Presence of ammonium groups makes the polymer into salts and increases the permeability. Hence, the combination of chitosan and ERL 100 will greatly helpful for transdermal application in terms of mucoadhesive property, drug diffusion, and permeability.

To the best of our knowledge, no report is available in literature on the well-designed transdermal matrix formulation containing T. arjuna extract. Conventional dosage forms of T. arjuna such as Arjunaristh, Arjuna Ghritha, Arvindasava, tablet, and capsule used in the treatment of different cardiovascular diseases. However, they face a problem such as first-pass metabolism, gastritis, constipation, stability, and low therapeutic efficacy. To overcome this problem, an attempt was made to prepare transdermal matrix formulation containing different polymer components to ensure satisfactory drug release with the use of polymer and thereby to avoid first-pass metabolism and prolong the duration of action for the treatment of chronic ailments such as cardiovascular disorder.

\section{METHODS}

Materials

The stem bark of T. arjuna was collected from Sahyadri Valley, Western Maharashtra region, Kolhapur Dist. (Maharashtra, India) in the month 
of August 2016 and identification was made by Dr. M. M. Lekhak, Department of Botany, Shivaji University, Kolhapur. A voucher specimen of the plant is deposited in the herbarium, Department of Botany with an accession number DTG 001. Chitosan was provided as a gift sample from Mahtani Chitosan Pvt., Ltd., Gujarat, India, and ERL 100 from Loba Chemie Pvt., Ltd., Mumbai, India, was used. All other chemicals used were of analytical grade.

\section{Formulation of T. arjuna transdermal matrix system}

The transdermal patches were prepared by solvent evaporation technique. The transdermal patches were composed of Chitosan:ERL100 in requisite ratio and allowed to swell for about $6 \mathrm{~h}$ solvent mixture (1:1 water and methanol). $2 \mathrm{ml}$ glycerin was incorporated as a plasticizer and $2 \mathrm{ml}$ dimethyl sulfoxide added as permeation enhancer. The extract solution was added to the polymeric solution mixed both solutions and stirred on magnetic stirrer to an accomplished homogeneous mixture. The resulting solution was poured in a Petri dish. The solvent was allowed to evaporate at $40^{\circ} \mathrm{C}$ for $24 \mathrm{~h}$ to obtain the medicated transdermal patch. The prepare transdermal patches were store in a desiccator until further use. A total of 9 batches were prepared by $3^{2}$ factorial design as per Table 1. Composition of S1-S9 batches is depicted in Table 2 .

\section{Physicochemical compatibility}

Fourier transform infrared (FTIR) spectroscopy study was conducted with the help of Shimadzu FTIR-8400S FTIR spectrometer and spectra were recorded in the range of $4000-400 \mathrm{~cm}^{-1}$ [11].

\section{Evaluation of T. arjuna transdermal matrix system}

Visual

The visual of matrix transdermal patch parameters is color, odor, texture, and film flexibility [12].

\section{Weight variation}

The weight variation five patches were weighed on an electronic balance, and the average of weight was taken [12]

\section{Film thickness}

The thickness of films was measured by micrometer screw at five different sites, and average of five readings was taken [12].

Table 1: Formulation design of transdermal matrix system

\begin{tabular}{lll}
\hline Batch code & \multicolumn{2}{l}{ Independent variables } \\
\cline { 2 - 3 } & $\mathbf{X}_{\mathbf{1}}$ (Chitosan) & $\mathbf{X}_{2}$ (ERL 100) \\
\hline S1 & -1 & -1 \\
S2 & -1 & 0 \\
S3 & -1 & +1 \\
S4 & 0 & -1 \\
S5 & 0 & 0 \\
S6 & 0 & +1 \\
S7 & +1 & -1 \\
S8 & +1 & 0 \\
S9 & +1 & +1 \\
\hline
\end{tabular}

\section{Moisture uptake}

The percentage of moisture uptake was calculated as the difference between final and initial weight with respect to initial weight [12]

\section{Folding endurance}

The folding endurance was measured manually for prepared films. A strip of film was folded at the same place till it broke. The number of times the film can be folded at the same place without breaking was the folding endurance value [13].

\section{Drug content}

A $0.1 \mathrm{~mm}$ thickness of the film was cut and put it into a $100 \mathrm{ml}$ phosphate buffer $(\mathrm{pH}$ 7.4) and ultrasonicated for $15 \mathrm{~min}$ with a stirrer. After filtration, the drug was estimated spectrometrically at a wavelength of $276 \mathrm{~nm}$ and determined the drug content compared using the calibration curve of the extract [12].

\section{In vitro diffusion studies}

The in vitro diffusion studies were carried out using a Franz diffusion (FD) cell. T. arjuna transdermal matrix formulation was applied on the cellophane membrane which was placed between donor and receptor compartment of the FD cell. Phosphate buffer pH 7.4 was used as a dissolution media. The temperature of the cell was maintained at $37^{\circ} \mathrm{C}$ by circulating water jacket. This whole assembly was kept on a magnetic stirrer, and the solution was stirred continuously using a magnetic bead. A similar blank set was run simultaneously as a control. Sample $(1 \mathrm{ml})$ was withdrawn at $60 \mathrm{~min}, 240 \mathrm{~min}, 420 \mathrm{~min}, 600 \mathrm{~min}$, and $720 \mathrm{~min}$ and replaced with equal amounts of fresh dissolution media. Samples were analyzed spectrophotometrically at $276 \mathrm{~nm}$ and the cumulative percentage release was calculated [14].

\section{Ex vivo diffusion studies}

The ex vivo release study was carried out in a FD cell using skin. Male goat free from any visible sign of the disease was selected. The goat dorsal skin was brought from slaughterhouse. The dorsal hair was removed, and the skin was washed with distilled water. The dorsal skin of full-thickness was excised and adhering subcutaneous fat was removed. Epidermis facing the donor compartment was mounted on the donor compartment. Phosphate buffer $\mathrm{pH} 7.4$ was used as dissolution media. T. arjuna transdermal matrix formulation was placed on the skin, which was previously equilibrated by soaking in phosphate buffer pH 7.4 for $24 \mathrm{~h}$. The diffusion area of goat skin was $2.64 \mathrm{~cm}^{2}$. The temperature of the cell was maintained constant at $37^{\circ} \mathrm{C}$ by circulating water jacket. This whole assembly was kept on a magnetic stirrer and the solution was stirred continuously using a magnetic bead. A similar blank set was run simultaneously. The samples were withdrawn at suitable time intervals and replaced with equal amounts of fresh dissolution media. Samples were analyzed spectrophotometrically at $276 \mathrm{~nm}[14]$.

\section{Skin irritation studies}

Institutional Ethics Committee permission was obtained as per the CPCSEA guidelines (Approval No: BVCPK/CPCSEA/IAEC/01/23) for carrying out the study on animals. The albino rats (average weight 200-250 gm) were divided into two groups $(\mathrm{n}=3)$. Group I received

Table 2: Composition of S1-S9 batches of the transdermal matrix system

\begin{tabular}{llllllllll}
\hline Batches & S1 & S2 & S3 & S4 & S5 & S6 & S7 & S8 & S9 \\
\hline Chitosan (mg) & 300 & 300 & 300 & 400 & 400 & 400 & 500 & 500 & 500 \\
ERL 100 (mg) & 300 & 400 & 500 & 300 & 400 & 500 & 300 & 400 & 500 \\
Water: methanol (ml) & $1: 1$ & $1: 1$ & $1: 1$ & $1: 1$ & $1: 1$ & $1: 1$ & $1: 1$ & $1: 1$ & $1: 1$ \\
$\begin{array}{l}\text { Glycerin (ml) } \\
\text { DMSO (ml) }\end{array}$ & 2 & 2 & 2 & 2 & 2 & 2 & 2 & 2 & 2 \\
$\begin{array}{l}\text { Extract solution } \\
\text { T. arjuna extract (mg) }\end{array}$ & 2 & 2 & 2 & 2 & 2 & 2 & & 2 & 500 \\
Water (ml) & 500 & 500 & 500 & 500 & 500 & 500 & 500 & 500 \\
& q.s. & q.s. & q.s. & q.s. & q.s. & q.s. & q.s. & q.s. & q.s. \\
\hline
\end{tabular}


prepared T. arjuna transdermal matrix formulation and Group II received $0.8 \% \mathrm{v} / \mathrm{v}$ aqueous solution of formalin as a standard irritant. At 24 and $72 \mathrm{~h}$, after test article application, the test sites were examined for dermal reactions in accordance with the Draize scoring criteria [15].

\section{Stability studies}

The prepared T. arjuna transdermal matrix formulations were packed in aluminum collapsible tubes and subjected to stability studies at $25^{\circ} \mathrm{C} / 60 \% \mathrm{RH}, 30^{\circ} \mathrm{C} / 65 \% \mathrm{RH}$, and $40^{\circ} \mathrm{C} / 75 \% \mathrm{RH}$ for 3 months. Samples were withdrawn at 15 day time intervals and evaluated for physicochemical properties and extract content [16].

\section{RESULTS AND DISCUSSION}

\section{Physicochemical compatibility}

The FTIR spectrum of pure extract showed characteristic peaks at $3386.094 \mathrm{~cm}^{-1}$ (broad, intermolecular hydrogen bonded, $\mathrm{O}-\mathrm{H}$ stretch), $2933.937 \mathrm{~cm}^{-1}$ (C-H stretch), $1680.805 \mathrm{~cm}^{-1}$ (Aromatic C=0 bend), $1439.529 \mathrm{~cm}^{-1}$ ( $\mathrm{C}=\mathrm{C}$ stretch), and $1282.533 \mathrm{~cm}^{-1}$ (C-O stretch). This characteristic peak may show the presence of alcohol and ethereal function groups, and also the presence of the aromatic ring. The FTIR spectrum of T. arjuna transdermal matrix formulation showed few minor shifting of peaks but no major changes. The FTIR spectrum of pure extract and formulation is depicted in Figs. 1 and 2, respectively.

\section{Evaluation of $T$. arjuna transdermal matrix system}

The results of the evaluation of various visual and physicochemical parameters of the $T$. arjuna transdermal matrix are presented in Tables 3 and 4 .

\section{In vitro diffusion studies}

The study showed the release of the drugs from its transdermal matrix formulation can be ranked in the following ascending order: S3 $>$ S1 $>\mathrm{S} 2>\mathrm{S} 4>\mathrm{S} 5>\mathrm{S} 6>\mathrm{S} 7>\mathrm{S} 8>\mathrm{S} 9$, where the amounts of the extract released after 720 min were $74.56 \%, 80.32 \%, 82.32 \%, 85.25 \%, 85.98 \%$, $86.17 \%, 91.58 \%, 91.68 \%$, and 92.13\%, respectively. Formulation S3

Table 3: Visual evaluation of T. arjuna transdermal matrix formulations

\begin{tabular}{lllll}
\hline Batch & Color & Odor & Texture & Flexibility \\
\hline S1 & Yellowish white & Odorless & Flat surface & Flexible \\
S2 & Yellowish white & Odorless & Flat surface & Flexible \\
S3 & Yellowish white & Odorless & Flat surface & Flexible \\
S4 & Yellowish white & Odorless & Flat surface & Flexible \\
S5 & Yellowish white & Odorless & Flat surface & Flexible \\
S6 & Yellowish white & Odorless & Flat surface & Flexible \\
S7 & Yellowish white & Odorless & Flat surface & Flexible \\
S8 & Yellowish white & Odorless & Flat surface & Flexible \\
S9 & Yellowish white & Odorless & Flat surface & Flexible \\
\hline
\end{tabular}

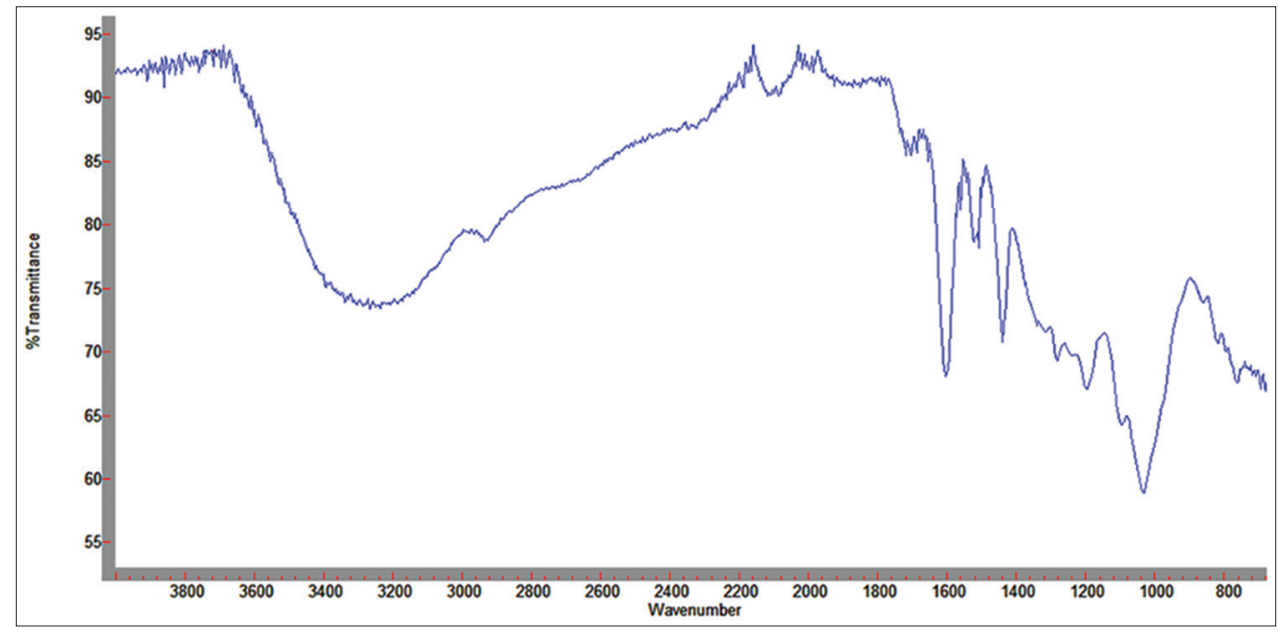

Fig. 1 The Fourier transform infrared spectrum of pure extract

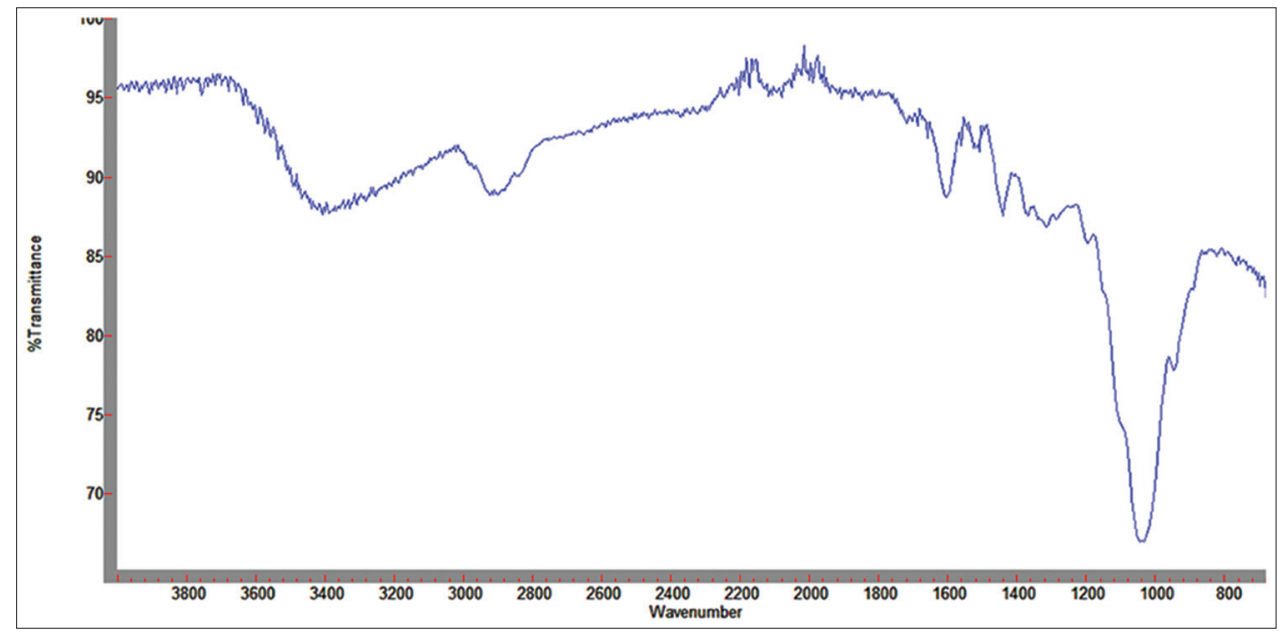

Fig. 2 The Fourier transform infrared spectrum of formulation 
Table 4: Physicochemical evaluation and drug content

\begin{tabular}{|c|c|c|c|c|c|}
\hline \multirow[t]{2}{*}{ Batch } & \multicolumn{5}{|l|}{ Physicochemical parameter } \\
\hline & Tensile strength $\left(\mathrm{Kg} / \mathrm{cm}^{2}\right)$ & Thickness (mm) & Moisture uptake (\%) & Folding endurance & Drug content (\%) \\
\hline S1 & $0.112 \pm 0.02$ & $0.12 \pm 0.02$ & $3.14 \pm 0.005$ & $109 \pm 1.52$ & $97.33 \pm 0.02$ \\
\hline S2 & $0.156 \pm 0.03$ & $0.14 \pm 0.01$ & $3.20 \pm 0.020$ & $111 \pm 1.08$ & $98.15 \pm 0.01$ \\
\hline S3 & $0.179 \pm 0.01$ & $0.18 \pm 0.01$ & $2.29 \pm 0.026$ & $120 \pm 1.08$ & $99.65 \pm 0.01$ \\
\hline S4 & $0.140 \pm 0.01$ & $0.12 \pm 0.01$ & $3.06 \pm 0.020$ & $116 \pm 1.00$ & $98.15 \pm 0.02$ \\
\hline S5 & $0.124 \pm 0.02$ & $0.13 \pm 0.02$ & $3.07 \pm 0.028$ & $110 \pm 1.51$ & $97.31 \pm 0.01$ \\
\hline S6 & $0.139 \pm 0.02$ & $0.14 \pm 0.02$ & $3.60 \pm 0.043$ & $101 \pm 1.46$ & $97.95 \pm 0.02$ \\
\hline S7 & $0.140 \pm 0.03$ & $0.15 \pm 0.01$ & $4.28 \pm 0.020$ & $105 \pm 1.21$ & $97.64 \pm 0.01$ \\
\hline S8 & $0.159 \pm 0.02$ & $0.16 \pm 0.03$ & $3.09 \pm 0.057$ & $100 \pm 1.00$ & $96.23 \pm 0.01$ \\
\hline S9 & $0.189 \pm 0.01$ & $0.22 \pm 0.01$ & $4.22 \pm 0.005$ & $107 \pm 1.08$ & $99.01 \pm 0.01$ \\
\hline
\end{tabular}

*All the values are given in mean \pm SD $(n=3)$, SD: Standard deviation

Table 5: Cumulative percent release

\begin{tabular}{|c|c|c|c|c|c|c|c|c|c|}
\hline Time (min) & S1 & $\mathrm{S} 2$ & S3 & S4 & S5 & S6 & S7 & S8 & S9 \\
\hline 60 & $10.26 \pm 0.011$ & $11.50 \pm 0.033$ & $11.02 \pm 0.012$ & $12.32 \pm 0.011$ & $13.94 \pm 0.001$ & $14.34 \pm 0.063$ & $15.23 \pm 0.023$ & $15.56 \pm 0.005$ & $17.13 \pm 0.012$ \\
\hline 240 & $23.20 \pm 0.001$ & $23.01 \pm 0.012$ & $27.47 \pm 0.011$ & $30.12 \pm 0.014$ & $30.44 \pm 0.001$ & $31.11 \pm 0.011$ & $31.32 \pm 0.002$ & $34.01 \pm 0.012$ & $35.15 \pm 0.015$ \\
\hline 420 & $44.11 \pm 0.002$ & $46.45 \pm 0.021$ & $46.45 \pm 0.001$ & $47.78 \pm 0.045$ & $48.45 \pm 0.052$ & $48.01 \pm 0.057$ & $48.78 \pm 0.005$ & $51.56 \pm 0.021$ & $52.45 \pm 0.030$ \\
\hline 600 & $62.54 \pm 0.068$ & $63.46 \pm 0.004$ & $60.44 \pm 0.068$ & $67.14 \pm 0.059$ & $68.35 \pm 0.057$ & $68.65 \pm 0.058$ & $74.25 \pm 0.015$ & $75.23 \pm 0.042$ & $78.19 \pm 0.056$ \\
\hline 720 & $80.32 \pm 0.011$ & $82.32 \pm 0.011$ & $74.56 \pm 0.055$ & $85.25 \pm 0.078$ & $85.98 \pm 0.001$ & $86.17 \pm 0.001$ & $91.58 \pm 0.003$ & $91.68 \pm 0.011$ & $92.13 \pm 0.035$ \\
\hline
\end{tabular}

*All the values are given in mean \pm SD $(n=3)$, SD: Standard deviation

showed better prolonged release than other formulations [17]. Results are given in Table 5 .

\section{Ex vivo diffusion studies}

From in vitro diffusion studies, it is evident that batch S3 showed better drug release up to $12 \mathrm{~h}$. Hence, by consideration of factorial design and overall physicochemical parameters results, batch S3 was optimized and used for ex vivo analysis. Ex vivo diffusion study of optimized S3 batch resulted in drug release $69.12 \pm 0.02 \%$ up to $12 \mathrm{~h}$.

\section{Skin irritation studies}

Institutional Ethics Committee permission was obtained as per the CPCSEA guidelines. The test sites were examined for dermal reactions in accordance with the Draize scoring criteria. Skin irritation study resulted no allergic symptoms such as inflammation, redness, and irritation appeared on albino rats up to $72 \mathrm{~h}$ albino rats which indicate the suitability of prepared formulations for topical application.

\section{Stability studies}

T. arjuna transdermal matrix formulations were subjected to stability studies at $25^{\circ} \mathrm{C} / 60 \% \mathrm{RH}, 30^{\circ} \mathrm{C} / 65 \% \mathrm{RH}$, and $40{ }^{\circ} \mathrm{C} / 75 \% \mathrm{RH}$ for 3 months. All the prepared formulations were found to be stable upon storage for 3 months; no change was observed [18].

\section{CONCLUSION}

In the present study, T. arjuna transdermal matrix formulations were prepared. On the evaluations and FTIR study, all the formulas showed good uniformity and acceptability. It was concluded that batch S3 is the optimized formulation for $12 \mathrm{~h}$ study period. Stability studies of the drug formulations proved that the drug was stable in the transdermal matrix formulations for the study period. Therefore, it can be concluded that the prepared transdermal matrix has the potential for transdermal drug delivery of T. arjuna with improved permeation profile for a longer period of time, thereby increasing the patient compliance.

\section{AUTHORS' CONTRIBUTIONS}

Both the authors were equally involved in the drafting, gathering information, and design of the framework of the manuscript.

\section{CONFLICTS OF INTEREST}

Nil.

\section{REFERENCES}

1. Shankar R, Tiwari V, Mishra CP, Singh CK, Sharma D, Jaiwal S. Formulation and evaluation of ketoconazole nanoemulsion gel for topical delivery. Am J Pharm Tech Res 2015;5:445-62.

2. Ahad A, Aqil M, Kohli K, Sultana Y, Mujeeb M, Ali A. Transdermal drug delivery: The inherent challenges and technological advancements. Asian J Pharm Sci 2010;5:276-89.

3. Ahad A, Al-Jenoobi FI, Al-Mohizea AM, Akhtar N, Raish M, Aqil M, et al. Systemic delivery of $\beta$-blockers via transdermal route for hypertension. Saudi Pharm J 2015;23:587-602.

4. Shingade GM, Quazi A, Sabale PM, Grampurohit ND, Gadhave MV, Jadhav SL, et al. Review on: Recent trend on transdermal drug delivery system. J Drug Deliv Ther 2012;2:66-76.

5. Ram A, Lauria P, Gupta R, Kumar P, Sharma VN. Hypocholesterolaemic effects of Terminalia arjuna tree bark. J Ethnopharmacol 1997;55:165-69.

6. Bachaya HA, Iqbal Z, Khan MN, Jabbar A, Gilani AH, Din IU. In vitro and in vivo anthelmintic activity of Terminalia arjuna bark. Int J Agric Biol 2009;11:273-8

7. Phanikumar G, Navya K, Ramya EM, Venkataramana M, Anand T, Anilakumar KR. DNA damage protecting and free radical scavenging properties of Terminalia arjuna bark in PC-12 cells and plasmid DNA. Free Radic Antioxid 2013;3:35-9.

8. Dwivedi S. Terminalia arjuna wight and amp; Arn. a useful drug for cardiovascular disorders. J Ethnopharmacol 2007;114:114-29.

9. Gaikwad D, Jadhav N. A review on biogenic properties of stem bark of Terminalia arjuna: An update. Asian J Pharm Clin Res 2018;11:35-9.

10. Prabhakara P, Koland M, Vijaynarayana K, Harish NM, Shankar G, Ahmed MG. Preparation and evaluation of transdermal patches of papaverine hydrochloride. Int J Res Pharm Sci 2010;1:259-66.

11. Patel RR, Patel ZK, Patel KR, Patel MR. Formulation and evaluation of microemulsion based gel of ketoconazole. Int J Univers Pharm Bio Sci 2014;3:93-111

12. Derie DV, Burade KB, Kotwal RS, Galkwad VB. Formulation and evaluation of microemulsion based gel for topical delivery of ketoconazole. Indian Drugs 2008;45:138-40.

13. Jufri M, Natalia M. Physical stability and antibacterial activity of black cumin oil (Nigella sativa L.) nanoemulsion gel. Int J Pharm Tech Res 2014;6:1162-9.

14. Leal LB, Cordery SF, Delgado-Charro MB, Bunge AL, Guy RH. Bioequivalence methodologies for topical drug products: In vitro and ex vivo studies with a corticosteroid and an anti-fungal drug. Pharm Res 2017;34:730-7.

15. Pimolphan P, Piyapan S, Porntip P, Wijit B, Benchaphorn L, Chayada K, et al. Proretinal nanoparticles: Stability, release, efficacy, and irritation. Int J Nanomed 2016;11:3277-86. 
16. Khatab A, Ismail S. Formulation and evaluation of oxiconazole nitrate mucoadhesive nanoemulsion based gel for treatment of fungal vaginal infection. Int J Pharm Pharm Sci 2016;8:34-40.

17. Padula C, Colombo G, Nicoli S, Catellani PL, Massimo G, Santi P, et al. Bioadhesive film for the transdermal delivery of lidocaine: In vitro and in vivo behavior. J Control Release 2003;88:277-85.

18. Giongo JL, Vaucher RD, Ourique AF, Steffler MC, Frizzo CP, Hennemman B, et al. Development of nanoemulsion containing Pelargonium graveolens oils: Characterization and stability study. Int J Pharm Pharm Sci 2016;5:271-6. 